\title{
ACADEMIA $\mid$ Letters \\ Reflecting on Ones Extended Digital Self as an Online Facilitator.
}

Stephen J Hall

Our sense of who we are as educators has been pushed into change, by the onslaught of CoVid 19. The pandemic has pushed change to an extent that teachers may have to consider not only how we appear on- screen, but also who we are as 'digitally extended' individuals (Parkinson et al, 2017) as we present ourselves through one of the many online delivery platforms. Many have been stretched through much new learning to acquire what may be novel lesson preparation and presentation skills. In fact, the online nature of having to rapidly address classroom change "showed that that the meaningful transfer of skills depends on the interaction which teachers and trainers or teacher educators develop in a collegial, rather than a hierarchical exchange" (Hall, 2017). We all know that there has been much learning from each other as it is now a scenario of "lights, action and roll it". Such changes may stimulate reflection about whom we are as online facilitators, beyond what we look like as a well-lit "talking head". Working at home, as this writer has had to do for eleven months, and still counting, has provided space, normally taken by the commute, to self- reflect on learning in action. Professional preparation has been a space of hastened change and reflection into being an educator.

\section{Delving into self-reflection}

Self- reflection may include how we critique our own pedagogy or teaching and facilitation philosophy, as described in detail by Farrell (2013). It can be useful to ask how our own identity and values as an educator/ learner and netizen impact on how we teach, organise information flows or facilitate learning through interaction. Such self-examination may be

Academia Letters, February 2021 @2021 by Academia Inc. — Open Access — Distributed under CC BY 4.0

Corresponding Author: Stephen J Hall, stephenh@sunway.edu.my

Citation: Hall, S.J. (2021). Reflecting on Ones Extended Digital Self as an Online Facilitator. Academia Letters, Article 221. https://doi.org/10.20935/AL221. 
especially poignant as the transition to online or hybrid learning has thrust our own learning and teaching styles into meeting 'pushed change'.

As so much has moved online, and may be here to stay, we many need to begin to look at our identity as a 'digitally extended' educator (Belk, 2016; Parkinson et al. 2017'. This concept includes all we do online, including commerce which is a source of data for many and more obviously how we co-construct our identity online through likes, comments, group choices and interaction. Whether we like it or not many of our own online savvy learners will engage in digital forensics to discover more about the face on screen who is asking then to engage in academic work. The extended digital self is more than what is carefully curated for an institution's staff page and the use of clever virtual backgrounds.

Our online identity is readily accessible, as Cambridge Analytica and Google well know, but how much of it are we actively moulding to assert and present our professional identity and values as an educator? What are we foregrounding online, consciously or less obviously? Is it a professional identity which online learners are keen to know? All netizens soon discover that there is more than one's visual image, as various social media platforms are revealing to anyone who cares to look and probe beyond Google searches (Hall, 2018a). Extensive details of this and issues of disclosure in the digital literacy can be found in Fulton and McGuiness's insightful work (2016). One useful exercise with learners is to ask them to reflect on their individual 'digital footprint" and how that relates to future employers' needs.

Another useful approach for educators as online actors, in both senses of the word, is to do a brief internal audit: to reflect. Some of this self- questioning may include how much time do we give to being online consumers, forwarders, group linkers, communicators or creators? What value adds are we contributing online, as educators? Understanding our own activity and seeing what online interactions are most meaningful may provide insights into what is engaging online and what appeals visually, because visuals and sound are dominant input. Visual literacy is in itself an underrated vital area worthy of further exploration in designing engaging interactive materials. In summary, knowing ourselves and the limits or areas of our own online presence may provide a basis for understanding our learners who may see Zoom lessons, Teams groups and Facebook as relics in the world of highly interactive Snap Chat and Tik Tok.

\section{Reflecting on Facilitating Interactivity}

An important element of language teaching has always been interactivity, and now with so many of us teaching remotely, adding interactivity and engagement to virtual classrooms is a necessity. Research suggests that student to student interaction and interaction with the facil-

Academia Letters, February 2021 @2021 by Academia Inc. — Open Access — Distributed under CC BY 4.0

Corresponding Author: Stephen Hall, stephenh@sunway.edu.my

Citation: Hall, S. (2021). Reflecting on Ones Extended Digital Self as an Online Facilitator. Academia Letters, Article 221. https://doi.org/10.20935/AL221. 
itator remain central to online engagement and achieving learning outcomes (Moore, 2014; $\mathrm{Hu} \& \mathrm{Li}, 2017)$. Visual interaction is also clearly important. From a practical viewpoint, less effective bandwidth often means turning off the video and this creates engagement difficulties. At the very least, one needs to start with videos on, as it is really challenging to relate to a series of initials on screen. Experience suggests that starting each session with an interactive task or movement game not only sets a tone for varying the use of video, but also provides a gauge of online bandwidth capacity. Yet real engagement involves interactive tasks, peer to peer learning and positive prompt feedback. Lesson planning has therefore had to be restructured to avoid a one-way transmission mode in what can be termed the talking head mode. Let us turn to interactivity and ways of building that.

Interactive tasks which create involvement through a cognitive challenge can be used in both synchronous and asynchronous modes. The recorded sessions provide reference and enable flipped classroom learners, who may be more introverted, to learn at their own pace (Hu \& Li, 2017), while live sessions certainly need short tasks interwoven into them. In reflecting on interactivity, I shall not refer to varied modes of learner output such as blogs, wikis, e portfolios, U Tube, Facebook groups and visual content creation tools such as Canva, all of what heighten the importance of visual literacy. More holistically, I would like to suggest that there is vital role for shorter, engaging online tasks which provide cognitive challenge, especially in live sessions which everyone wants to go beyond curating a long listening session.

Setting up short tasks with digital tools which move online education beyond transmission of content has involved much facilitator learning. Examples include visual creativity tools such as digital Mind Maps, incorporating phone aps, collaborative platforms, polls and quizzes (see Dailey- McHebert, 2018). It has been rapid learning in which facilitators have incorporated collaborative tools like Padlet, Socrative and Kahoot to name but a few. There is a plethora of choices with quiz apps such as Quizz and polling tools such as Poll Daddy and Mentimeter. This writers' colleagues reflected on what engages the Tok-Tok and Whats Ap crowd, so we worked with varying tasks in online lessons through such interactive tools, a few of which have been mentioned. A comprehensive listing of useful tools can be found at https://www.toptools4learning.com/, to name but one source.

What these collaborative tools do is foster interactivity and break up the use of online delivery so as to avoid creating another long, listening exercise. Student evaluations and initial research within this writer's University English for Specific and Academic Purposes courses suggest that the use of interactive tools, such as mentioned above, help engagement and develop a sense of being part of what may otherwise be a fragmented, distant, online experience. The polls and quizzes also enable facilitators to get feedback and reflection from learners on what they have internalised, while providing a measure of learning uptake.

Academia Letters, February 2021 C2021 by Academia Inc. — Open Access — Distributed under CC BY 4.0

Corresponding Author: Stephen Hall, stephenh@sunway.edu.my

Citation: Hall, S. (2021). Reflecting on Ones Extended Digital Self as an Online Facilitator. Academia Letters, Article 221. https://doi.org/10.20935/AL221. 
Clearly face to face interaction is missed by all, but in this time of pushed change, we have little choice but to embrace new modalities and stay reflective about the learning that we as educators co-construct with our learners. The first point to start with is to know oneself as a digitally extended netizen, by understanding one's own online presence and learning style and then broadening this to embrace pushed change which focuses on interactive learning.

\section{References}

Belk. R.I (2016) Extended self and the digital world. Current Opinion in Psychology, 10, 50-54, https://doi.org/10.1016/j.copsyc.2015.11.003.

Dailey-Hebert, A.( 2018) Maximizing Interactivity in Online Learning: Moving beyond Discussion Boards. Journal of Educators Online, 15, 3 Dec 2018. Accessed 1 Dec.2020.

Farrell, T. S. C. (2013). Reflective teaching. Alexandria, VA: TESOL International Association.

Fulton C. and McGuiness, C. (2016). Digital Detectives. Solving information in an Online World. Chandos Publishing, https://doi.org/10.1016/B978-0-08-100124-0.01001-1

Hall, S.J. (2018 a) Beyond teacher transmission and Googling information to more creative language learning. In (Eds.) V. Novita, D.P.Saraswati, M.C Wulandri et al. Proceedings of The 6th Undergraduate Conference on ELT, Linguistics and Literature. Learning English in the Modern Era. pp. 1-9. Yogyakarta: Sanata Dharma Press.

Hall. S.J. (2018 b) In-Service Training in Preparing Native English Speaker Teachers and Non-Native English Speaker TeachersIn (Ed.) Liontas, J. TESOL Encyclopaedia of English Language Teaching. Wiley, DOI: 10.1002/9781118784235

Hu,M. \& Li,M. (2017) Student Engagement in Online Learning: A Review in 2017 International Symposium on Educational Technology (ISET), Hong Kong, 2017 pp. 39-43.doi: 10.1109/ISET.2017.17 url: https://doi.ieeecomputersociety.org/10.1109/ISET.2017.17

Moore, J. (2014) Effects of Online Interaction and Instructor Presence on Students' Satisfaction and Success with Online Undergraduate Public Relations Courses. Journalism \& Mass Communication Educator. 69, 271-288. 10.1177/1077695814536398.

Parkinson B, Millard DE, O'Hara K, Giordano R. 2018 The digitally extended self: A lexicological analysis of personal data. Journal of Information Science;44,4, 552-565.

Academia Letters, February 2021 @2021 by Academia Inc. — Open Access — Distributed under CC BY 4.0

Corresponding Author: Stephen Hall, stephenh@sunway.edu.my

Citation: Hall, S. (2021). Reflecting on Ones Extended Digital Self as an Online Facilitator. Academia Letters, Article 221. https://doi.org/10.20935/AL221. 
doi:10.1177/0165551517706233

https://www.toptools4learning.com/

Academia Letters, February 2021 C2021 by Academia Inc. — Open Access — Distributed under CC BY 4.0

Corresponding Author: Stephen Hall, stephenh@sunway.edu.my

Citation: Hall, S. (2021). Reflecting on Ones Extended Digital Self as an Online Facilitator. Academia Letters, Article 221. https://doi.org/10.20935/AL221. 